University of Nebraska - Lincoln

DigitalCommons@University of Nebraska - Lincoln

\title{
Effects of Concentrate Level and Pen Configuration on Performance of Boer Crossbred Goat Kids
}

M. E. Corrigan

Kansas State University

J. S. Drouillard

Kansas State University, jdrouill@k-state.edu

E. R. Loe

Kansas State University

B. E. Depenbusch

Kansas State University

M. J. Quinn

Kansas State University

Follow this and additional works at: https://digitalcommons.unl.edu/panhandleresext

Part of the Agriculture Commons

Corrigan, M. E.; Drouillard, J. S.; Loe, E. R.; Depenbusch, B. E.; and Quinn, M. J., "Effects of Concentrate Level and Pen Configuration on Performance of Boer Crossbred Goat Kids" (2008). Panhandle Research and Extension Center. 48.

https://digitalcommons.unl.edu/panhandleresext/48

This Article is brought to you for free and open access by the Agricultural Research Division of IANR at DigitalCommons@University of Nebraska - Lincoln. It has been accepted for inclusion in Panhandle Research and Extension Center by an authorized administrator of DigitalCommons@University of Nebraska - Lincoln. 


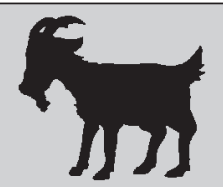

\title{
$E_{\text {ffects of Concentrate Level }}$ and Pen Configuration on Performance of Boer Crossbred Goat Kids
}

\author{
M. E. Corrigan, ${ }^{1}$ J. S. Drouillard, ${ }^{2}$ E. R. Loe,${ }^{3}$ B. E. Depenbusch, and M. J. Quinn \\ Department of Animal Sciences and Industry, Kansas State University, Manhattan 66506-1600
}

\begin{abstract}
One hundred eighty-one Boer-sired goat kids from dams of predominantly Spanish breeding $(17.6 \pm 2.34 \mathrm{~kg}$ initial $B W ; 177$ wethers, 4 doelings) were used to determine optimum inclusion level of concentrate in diets fed to goats in confinement. Effects of elevated loafing areas on performance were also examined. Goats were blocked by weight (2 blocks per treatment) and randomly assigned to 1 of 12 outdoor pens $\left(4.3 \mathrm{~m}^{2} ; 15\right.$ to 16 head/pen) with concrete floors. Pens of goats were randomly assigned, within block, to 1 of 6 treatments. A $2 \times 3$ factorial arrangement was used with factors consisting of pen configuration, defined as the presence or absence of a concrete structure ( $45 \mathrm{~cm}$ high, $75 \mathrm{~cm}$ wide, and $150 \mathrm{~cm}$ long) in the center of the pen, and level of concentrate in the diet (50, 70 , or 90\%). Goats were fed diets ad libitum twice daily for $126 \mathrm{~d}$. Dry matter intake decreased linearly $(P<0.01)$ and gain efficiency increased linearly $(P=$ $0.03)$ as the proportion of concentrate in the diet increased. Average daily gain

\footnotetext{
${ }^{1}$ Current address: Animal Science Department, University of Nebraska, Lincoln, NE 68583-0908

${ }^{2}$ Corresponding author: jdrouill@ksu.edu

${ }^{3}$ Current address: Brookings, SD 57006.
}

$(P<0.01)$ and final $B W(P=0.02)$ responded quadratically to concentrate level, and were greatest for goats fed $70 \%$ concentrate. Presence of an elevated loafing area in the pen tended to decrease DMI $(P=0.09)$. Increasing the level of concentrate in the diet generally improved performance of Boer-crossbred goat kids fed in confinement.

Key words: goat, concentrate level, behavior

\section{INTRODUCTION}

The utility of goats in managing undesirable vegetation has been well established. Many studies have demonstrated the ability of goats to substantially decrease brush species in infested pastures while significantly increasing vegetative growth of favorable grass and legume species, thereby increasing the carrying capacity of pastures for other species of livestock (Townsend and Radcliffe, 1990; Essam Dabaan et al., 1997; Luginbuhl et al., 1998). In this function goats serve as a favorable alternative to herbicide application, which can pose both environmental and public perception concerns. Production efficiency in these systems, however, can be compromised.
Undersupply of goat meat in the United States has created an economic climate that favors increases in domestic production. Since 1994, the United States has been a net importer of goat meat, and in 2003 imports of goat meat reached 19 million pounds at a total value of $\$ 21.48$ million (Singh-Knights and Knights, 2005). Demand for goat meat in the United States is largely derived from consumption by various ethnic and religious groups. Recent population shifts have caused consumption of goat meat in the United States to rise more rapidly than that of any other meat. Because consumption of goat meat is tied to cultural practices, demand appears to be relatively inelastic (Singh-Knights and Knights, 2005). Although increasing numbers of meat goats is a logical solution to address the deficit in supply of goat meat in the United States, introduction of concentrate feeding also can increase supply of marketable product. Compared with other livestock species, relatively few studies have examined the use of high-concentrate diets for goat production and their impact on sensory attributes of goat meat. Moreover, observations of the effects of animal behavior and social hierarchy on production of meat goats 
are rare. This study was conducted to evaluate the effects of varying proportions of roughage and concentrate in the diet and the addition of elevated loafing areas on performance of Boercrossbred goat kids fed in confinement. A companion experiment examining the prevalence of Escherichia coli $\mathrm{O} 157$ in goats used in this study has been previously published (Fox et al., 2007). Additionally, a study has been previously published that compares the sensory traits of meat derived from a subsample of goats used in this study and goats consuming a browse-based diet (Ryan et al., 2007).

\section{MATERIALS AND METHODS}

\section{Animals and Experimental Design}

Procedures for this study were approved by the Kansas State University Institutional Animal Care and Use Committee. One hundred eightyone Boer-sired goat kids from dams that were of predominantly Spanish breeding (17.6 $\pm 2.34 \mathrm{~kg}$ initial BW; 177 wethers, 4 doelings) were transported (approximately $240 \mathrm{~km}$ ) to the Kansas State University Beef Cattle Research Center in Manhattan, Kansas, from pastures near Buffalo, Kansas. Within $24 \mathrm{~h}$ after arrival, each goat was individually identified with an ear tag and a BW was recorded. Goats were blocked by weight (heavy and light) and randomly assigned to 1 of 12 concrete-surfaced, outdoor pens $\left(4.3 \mathrm{~m}^{2} ; 15\right.$ to 16 animals/pen) that were equipped with feed bunks and automatic waterers that were fashioned using a bucket with a float attached to the water shut-off valve. A randomized complete block design with a $2 \times 3$ factorial arrangement was utilized. Factors consisted of pen configuration, defined as the presence or absence of an elevated loafing area (45 cm high, $75 \mathrm{~cm}$ wide, $150 \mathrm{~cm}$ long) in the pen, and 3 levels of concentrate in the $\operatorname{diet}(50,70$, or $90 \%$; DM basis; Table 1). A series of transition diets $(50,60,70,80$, and $90 \%$ concentrate) were used to adapt goats to the greater concentrate levels. Con-

\section{Table 1. Composition of diets fed for $126 \mathrm{~d}$ to Boer-crossbred goat kids housed in pens with or without an elevated loafing area (\% of DM) ${ }^{1}$}

\begin{tabular}{lccc} 
& \multicolumn{3}{c}{ Concentrate level, \% of dietary DM } \\
\cline { 2 - 4 } Item & 50 & 70 & 90 \\
\hline Ingredient & & & \\
Dry-rolled corn & 42.5 & 60.6 & 78.5 \\
Alfalfa hay & 49.8 & 29.8 & 9.9 \\
Corn steep liquor & 7 & 7 & 7 \\
Soybean meal & 0 & 1 & 2 \\
Limestone & 0.12 & 0.74 & 1.39 \\
Salt & 0.3 & 0.3 & 0.3 \\
Urea & 0.16 & 0.43 & 0.76 \\
Potassium chloride & 0 & 0.01 & 0.03 \\
Vitamin-mineral premix & 0.12 & 0.12 & 0.12 \\
Nutrient analysis & & & \\
CP, \% & 18.1 & 17.0 & 16.0 \\
Ca & 0.95 & 0.84 & 0.73 \\
P & 0.36 & 0.38 & 0.40 \\
Ca:P & 2.64 & 2.21 & 1.83 \\
\hline
\end{tabular}

${ }^{1}$ On d 113 , diets were reformulated to include $1 \%$ salt and $0.5 \%$ ammonium chloride. These changes were made to address problems with urolithiasis.

${ }^{2}$ Formulated to provide $0.1 \mathrm{mg} / \mathrm{kg}$ of $\mathrm{Co}, 8 \mathrm{mg} / \mathrm{kg}$ of $\mathrm{Cu}, 0.5 \mathrm{mg} / \mathrm{kg}$ of I, $50 \mathrm{mg} / \mathrm{kg}$ of $\mathrm{Mn}, 0.3 \mathrm{mg} / \mathrm{kg}$ of Se, $50 \mathrm{mg} / \mathrm{kg}$ of Zn, 2,595 IU/ $\mathrm{kg}$ of vitamin A, $22 \mathrm{IU} / \mathrm{kg}$ of vitamin $\mathrm{E}$, and $17 \mathrm{mg} / \mathrm{d}$ of monensin per goat.

sequently, goats fed $70 \%$ concentrate were introduced to their final diet by d 13, and goats fed $90 \%$ concentrate began receiving their final diet on $\mathrm{d}$ 22. Safeguard Goat Dewormer (Intervet, Millsboro, DE) was administered orally at a rate of $2 \mathrm{~mL} /$ goat on d 49 and 105. The elevated dose was used per the instructions of our animal veterinarian.

Diets were fed for $126 \mathrm{~d}$ as a TMR twice daily in amounts that were sufficient to not limit feed intake while minimizing waste. Weekly feed refusals were weighed back and DM content was determined using a $55^{\circ} \mathrm{C}$ oven. The alfalfa hay used in this study was purchased from a local farmer. The hay had been chopped through a 7.5-cm screen and the approximate particle size was between 4 and $7 \mathrm{~cm}$. On d 113, diets were reformulated to include $1 \%$ salt and 0.5\% ammonium chloride to address problems with urolithiasis.

Removal of goats due to urolithiasis occurred on d 82, 85, 87 (2 goats), $108,109,116,117,120$, and 121 of the study. Upon initial appearance of clinical signs of urolithiasis, goats were examined by a veterinarian. If appropriate, the urethral process of those goats was surgically amputated by a veterinarian. Goats that continued to exhibit signs of or experienced a reoccurrence of urolithiasis were removed from the study and killed. Following death or euthanasia of a goat for any reason, the animal was transported to the Kansas State University College of Veterinary Medicine Diagnostic Laboratory where a postmortem examination was performed to determine the cause of death or symptoms warranting euthanasia.

\section{Statistical Analysis}

Performance data were analyzed using the mixed procedure of SAS (Littell et al., 1996). Factors included in the model were concentrate level, pen configuration, and the interaction between concentrate level and pen configuration. The random variable was weight block. Orthogonal contrasts were used to detect linear 


\section{Table 2. Causes of death or euthanasia of Boer-crossbred goat kids fed diets containing 50,70 , or $90 \%$ concentrate and housed in pens with or without an elevated loafing area ${ }^{1,2}$}

\begin{tabular}{lcccc} 
& \multicolumn{3}{c}{ Concentrate level } & \\
\cline { 2 - 4 } Cause of death or euthanasia & $\mathbf{5 0}$ & $\mathbf{7 0}$ & $\mathbf{9 0}$ & P-value $^{\mathbf{3}}$ \\
\hline Urolithiasis (water belly) & 2 & 7 & 1 & 0.07 \\
Respiratory & 0 & 1 & 1 & 0.55 \\
Gastrointestinal parasites & 0 & 0 & 3 & 0.07 \\
Urinary tract infection & 1 & 0 & 0 & 1.00 \\
Digestive & 0 & 0 & 1 & 0.66 \\
Total & 3 & 8 & 6 & 0.26 \\
\hline
\end{tabular}

${ }^{1}$ Cause of death determined by the Kansas State University Veterinary Medicine Diagnostic Laboratory.

${ }^{2}$ No effect of loafing area on mortality rates was observed $(P \geq 0.54)$.

${ }^{3}$ Fisher's exact test.

and quadratic effects of concentrate level. No interactions between concentrate level and pen configuration were observed; thus only main effects are reported. Performance data were analyzed with dead animals excluded from the analysis and also with data from the dead animals included in the analysis. Final BW and ADG were assumed to be zero for goats that died or were killed when data from them were included in the analysis. On the day that goats that died were not in the pen, DMI was considered zero for those goats when calculating per head daily DMI. Data for goat mortalities were analyzed using Fisher's exact test in the PROC FREQ procedure of SAS.

\section{RESULTS AND DISCUSSION}

\section{Health Data}

Seventeen goats died or were killed (Table 2); 10 deaths were due to urolithiasis. Death loss of $9 \%$ was greater than expected, although only a $3 \%$ death loss was incurred for causes other than urolithiasis. Seven of the 10 goats that died from urolithiasis were fed the $70 \%$ concentrate diet and all 3 of the goats that died from gastrointestinal tract parasites were fed the $90 \%$ concentrate diet. There was a tendency for diet to effect the number of mortalities caused by urolithiasis and gastrointestinal tract parasites ( $P=0.07$ for both), but diet did not affect any other causes of death $(P>$ $0.26)$. Of the 7 goats that died from causes other than urolithiasis and gastrointestinal parasites, 2 were due to respiratory disease, one was due to infection of the urinary tract, and one was due to digestive problems. No effect of pen configuration on causes of mortality was observed $(P>0.54)$.

Reasons for the observation of a potential dietary effect on deaths caused by gastrointestinal tract parasites are unclear. Furthermore, the impact that possible subclinical internal parasite infestation in all treatment groups may have had on performance cannot be determined. Removal of goats from the study for complications due to gastrointestinal tract parasite infestation occurred on d 9, 82, and 117 of the study, and may indicate parasitic resistance to the anthelmintic used (Zajac and Gipson, 2000).

An analysis that included data from goats that had died or were killed was included primarily to demonstrate the variable effects that concentrate level in the diet appeared to have on urolithiasis. Goats have a propensity to sort feedstuffs, so in future experiments it would be useful to pellet diets fed to goats to ensure that the observed effects are due consumption of the total diet and not a result of sorting. The high incidence of urolithiasis in this study supports the observations made by Sato and Omori (1977) that goats are susceptible when fed diets high in phosphorus. Based on our subjective observations it appeared that goats fed the $70 \%$ concentrate diet were more inclined to sort their feed, consuming primarily concentrate. This observation is supported by the greater incidence of urolithiasis in goats fed the $70 \%$ concentrate diet (11.7\%) compared with urolithiasis incidence observed in those fed the $50 \%(3.3 \%)$ or $90 \%$ $(1.7 \%)$ diets. Moreover, the analyzed $\mathrm{Ca}: \mathrm{P}$ ratios of the mixed diets $(2.64$, 2.21 , and 1.83 for the 50,70 , and $90 \%$ concentrate diets, respectively; Table 1) were greater than the recommended Ca:P ratio of 1.5 (NRC 1981), indicating that sorting played a role in urolithiasis incidence. Because of the relatively high concentration of $\mathrm{Ca}$ in alfalfa hay $(1.77 \% \mathrm{DM}$ for the alfalfa hay used in this study), failure to consume alfalfa hay at a rate proportional to concentrate in the diet potentially caused the Ca:P ratio consumed to be less than recommended levels. Goetsch et al. (2003) allowed Alpine doelings ad libitum access to a concentrate mix $(72.8 \%$ ground corn, $15.2 \%$ soybean meal, $6 \%$ fish meal, and $6 \%$ dried molasses) and wheat hay offered separately and found that voluntary intake of the concentrate mix and wheat hay was 83.6 and $16.4 \%$ of diet DM, respectively. Goats fed the $70 \%$ concentrate diets in this study may have exhibited similar concentrate and forage intake patterns. The lesser incidence of urolithiasis in goats fed the $50 \%$ concentrate diet compared with goats fed the $70 \%$ concentrate diet may have been a consequence of limited access to concentrate with the $50 \%$ concentrate diet increasing intake of alfalfa hay. Additionally, the lesser incidence of urolithiasis in goats fed the $90 \%$ concentrate diet compared with goats fed the $70 \%$ concentrate diet was likely the result of limestone supplying a greater proportion of dietary $\mathrm{Ca}$ (Table 1 ), and the presumed 
Table 3. Performance and carcass characteristics of Boer crossbred goat kids fed diets containing 50, 70, or $90 \%$ concentrate and housed in pens with or without an elevated loafing area (animals that died during the study not included in analysis)

\begin{tabular}{|c|c|c|c|c|c|c|c|c|c|}
\hline \multirow[b]{2}{*}{ Item } & \multicolumn{3}{|c|}{ Concentrate level (\%) } & \multirow[b]{2}{*}{ SEM } & \multicolumn{2}{|c|}{ Pen configuration } & \multirow[b]{2}{*}{ SEM } & \multicolumn{2}{|c|}{$\begin{array}{c}\text { Concentrate level } \\
P \text {-value }\end{array}$} \\
\hline & 50 & 70 & 90 & & Flat & Elevated loafing area & & Linear & Quadratic \\
\hline Number of head ${ }^{1}$ & 58 & 52 & 54 & - & 82 & 82 & - & - & - \\
\hline Initial BW, kg & 17.58 & 17.44 & 17.59 & 2.34 & 17.49 & 17.59 & 2.34 & 0.97 & 0.45 \\
\hline Final BW, kg & 29.79 & 30.39 & 28.91 & 2.23 & 29.51 & 29.89 & 2.22 & 0.05 & 0.02 \\
\hline Daily gain, g & 97 & 103 & 90 & 2 & 95 & 98 & 1 & 0.04 & $<0.01$ \\
\hline $\mathrm{DMI},{ }^{2} \mathrm{~g} / \mathrm{d}$ & 923 & 830 & 735 & 45 & 848 & 811 & 44 & $<0.01$ & 0.97 \\
\hline $\mathrm{G}: \mathrm{F}$ & 0.1054 & 0.1241 & 0.1232 & 0.0081 & 0.1136 & 0.1216 & 0.0077 & 0.03 & 0.11 \\
\hline
\end{tabular}

${ }^{1}$ Seventeen goats died or were killed during the study.

${ }^{2}$ Effect of pen configuration, $P<0.09$.

inability of goats to sort limestone out of the diet. Therefore, Ca source particle size is a potentially important in finishing goat diets, although this may be less of a concern in diets containing lesser $(\leq 50 \%$ of DM) amounts of concentrate.

\section{Effects of Concentrate Level}

Performance data with dead goats excluded are shown in Table 3 . There were quadratic effects of concentrate level on final BW $(P=0.02)$ and daily gain $(P<0.01)$, with goats fed the $70 \%$ concentrate level having the greatest value for both variables and goats fed the $90 \%$ concentrate having the lowest value for both variables. Dry matter intake decreased linearly $(P<0.01)$ as level of concentrate in the diet increased, and gain efficiency improved linearly $(P=0.03)$ as level of concentrate in the diet increased.

Performance data including data from the 17 goats that died or were killed are presented in Table 4 . When data from these goats were included in the analysis, there was a linear decrease $(P<0.01)$ in DMI as level of concentrate in the diet increased, but no other performance variables were affected by treatment $(P \geq 0.13)$. However, the numerically greatest gains were observed in goats fed the $50 \%$ concentrate diet when data from all goats were included in the analysis.

When interpreting the results from this study, the possibility that subclinical urolithiasis may have affected performance must be recognized.
Goats fed the $70 \%$ concentrate diet would have been expected to be the most afflicted, as they exhibited the greatest symptoms of clinical urolithiasis. However, as mentioned above, daily gains responded quadratically $(P<0.01)$ for the goats that remained on the study for the entire $126 \mathrm{~d}$, with goats fed the $70 \%$ concentrate diet having the greatest daily gains. When data from goats that died are excluded, results from this experiment are similar to those of other experiments using increasing levels of concentrate in goat diets. Goetsch et al. (2003) observed that daily gain and G:F increased in Alpine doelings (fed 25,50 , or $75 \%$ concentrate) as level of concentrate in the diet increased. The authors reported that there were no statistical differences in

Table 4. Performance of Boer crossbred goat kids fed diets containing 50,70 , or $90 \%$ concentrate and housed in pens with or without an elevated loafing area (animals that died during the study included in analysis)

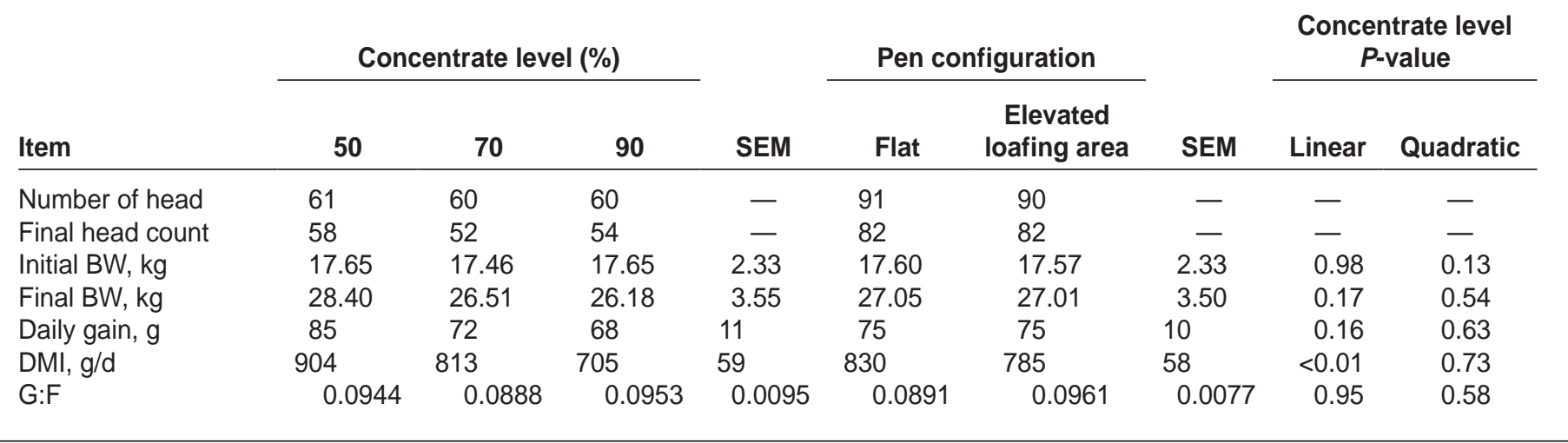


DMI, but numerically DMI was highest in goats consuming a $50 \%$ concentrate diet and lowest in goats consuming a 25 and $75 \%$ concentrate diet. Urge et al. (2004) reported increased ADG and G:F in goats fed diets containing $75 \%$ concentrate compared with goats fed a diet containing $50 \%$ concentrate during the initial 12 wk of the feeding trial, with DMI being less for goats fed $75 \%$ compared with $50 \%$ concentrate.

\section{Effects of Pen Configuration}

There were no effects of pen configuration on final $\mathrm{BW}, \mathrm{ADG}$, or $\mathrm{G}: \mathrm{F}$ $(P>0.10)$, but there was a tendency $(P=0.09)$ for DMI to be less in pens containing elevated loafing areas when data from goats that died were not included in the analysis (Table 3 ). All variables measured were similar between pen configurations when data from goats that died during the study were included in the analysis $(P \geq 0.13)$. Less DMI in pens that contained an elevated loafing area can potentially be explained on the basis that submissive animals sought refuge on the loafing area to avoid confrontation with socially dominant goats in the pen. This may have led to less frequent or shorter duration visits to the feed bunk for less aggressive goats. Barroso et al. (2000) demonstrated a linear hierarchical order in goat herds that influenced consumption of shrubs and forbs as well as production in goats allowed to graze during the day. Constant confinement of goats in this study may have exaggerated social stressors, thereby affecting eating behaviors. The observation of reduced intake coupled with similar ADG may indicate that concrete blocks removed some of the stress associated with social behavior of goats. Changes in eating behaviors in response to social stress in pigs have been described (Bornett et al., 2000; Hyun et al., 1998) and may provide some insight into observations in this study. Conversely, the loafing areas may have occupied goats and led to a reduction in feed wastage, as goats had a tendency to climb on and stand in the feed bunk.

\section{IMPLICATIONS}

Results from this study indicated an effect of concentrate level on incidence of urolithiasis in goats fed alfalfa hay as the roughage source. Therefore, eating behavior of goats should be considered when formulating diets and appropriate preventive measures are recommended. Data from goats that remained on the study for the entire 126-d period indicated that final BW and ADG respond quadratically to proportion of concentrate in diets with alfalfa hay as the roughage source. However, gain efficiency improved linearly with increasing concentrate level in those goats. Finally, the presence of an elevated loafing area tended to reduce DMI, possibly indicating an effect of behavior on eating patterns in goats. Results from this study indicate an effect of diet on incidence of urolithiasis in goats fed alfalfa hay as the roughage source. This was apparently due to sorting of the roughage and concentrate at the intermediate concentrate level, and proper dietary measures need to be taken to address potential urolithiasis problems.

\section{LITERATURE CITED}

Barroso, F. G., C. L. Alados, and J. Boza. 2000. Social hierarchy in the domestic goat: Effect on food habits and production. Appl. Anim. Behav. Sci. 69:35.

Bornett, H. L., C. A. Morgan, A. B. Lawrence, and J. Mann. 2000. The effect of group housing on feeding patterns and social behavior of previously individually housed growing pigs. Appl. Anim. Behav. Sci. 70:127.

Essam Dabaan, M., A. M. Magadlela, W. B. Bryan, B. L. Arbogast, E. C. Prigge, G. Flores, and J. G. Skousen. 1997. Pasture development during brush clearing with sheep and goats. J. Range Manage. 50:217.

Fox, J. T., M. Corrigan, J. S. Drouillard, X. Shi, R. D. Oberst, and T. G. Nagaraja. 2007. Effects of concentrate level of diet and pen configuration on prevalence of Escherichia coli O157 in finishing goats. Small Rumin. Res. 72:45.

Goetsch, A. L., G. Detweiler, T. Sahlu, J. Hayes, and R. Puchala. 2003. Effects of separate offering of forage and concentrate on feed intake and growth of Alpine doelings. Small Rumin. Res. 48:209.

Hyun, Y., M. Ellis, G. Riskowski, and R. W. Johnson. 1998. Growth performance of pigs subjected to multiple concurrent environmental stressors. J. Anim. Sci. 76:721.

Littell, R. C., G. A. Milliken, W. S. Stroup, and R. D. Walker. 1996. SAS System for Mixed Models. SAS Inst. Inc. Cary, NC.

Luginbuhl, J.-M., T. E. Harvey, J. T. Green Jr, M. H. Poore, and J. P. Mueller. 1998. Use of goats as biological agents for the renovation of pastures in the Appalachian region of the United States. Agrofor. Syst. 44:241.

NRC. 1981. Nutrient Requirements of Goats: Angora, Dairy, and Meat Goats in Temperate and Tropical Countries. Natl. Acad. Press, Washington, DC.

Ryan, S. M., J. A. Unruh, M. E. Corrigan, J. S. Drouillard, and M. Seyfert. 2007. Effects of concentrate level on carcass traits of Boer crossbred goats. Small Rumin. Res. 73:67.

Sato, H., and S. Omori. 1977. Incidence of urinary calculi in goats fed a high phosphorus diet. Jpn. J. Vet. Sci. 39:531.

Singh-Knights, D., and M. Knights. 2005. Feasibility of Goat Production in West Virginia: A Handbook for Beginners. West Virginia Univ. Davis College of Agriculture, Forestry, and Consumer Services. http:// www.ca.uky.edu/ANR/Agent\%20Resources/ pdf/WV\%20goat\%20pub.pdf Accessed Nov. 15, 2007.

Townsend, R. J., and J. E. Radcliffe. 1990 Lamb growth rates improve as goat to sheep ratio increases. Proc. N. Z. Grassl. Assoc. 52:115.

Urge, M., R. C. Merkel, T. Sahlu, G. Animut, and A. L. Goetsch. 2004. Growth performance by Alpine, Angora, Boer and Spanish wether goats consuming 50 or $70 \%$ concentrate diets. Small Rumin. Res. 55:149.

Zajac, A. M., and T. A. Gipson. 2000. Multiple anthelmintic resistance in a goat herd. Vet. Parasitol. 87:163. 